\title{
Is month of birth associated with cataract in later life?
}

\author{
John J Harding, Ruth van Heyningen
}

\begin{abstract}
Background-It has been suggested that season of birth might influence the susceptibility to cataract in later life. Methods-This hypothesis was investigated using data pooled from two casecontrol studies carried out in Oxfordshire.

Results/conclusion-The results showed no relation between month or season of birth and cataract in later life in an English population.

(Br f Ophthalmol 1998;82:526-527)
\end{abstract}

Cataract is a multifactorial disease with many known risk factors and some yet to be identified..$^{1-5}$ It is known that several age related conditions - for example, non-insulin dependent diabetes, are associated with low birth weight and therefore possibly related to poor nutrition in early life. ${ }^{6}$ Season of birth has been associated with other diseases and mortality. Professor Robert Weale (at the Oxford Congress) has suggested that season of birth might be associated with cataract in later life. Data from two case-control studies of cataract in Oxfordshire had included date of birth ${ }^{2}{ }^{3}$ so it was possible for us to test this hypothesis.

A total of 1940 subjects were interviewed in the two studies, 723 of them being cataract surgery patients. To determine age we had asked for date of birth and this was recorded for all subjects. The large numbers should be sufficient to assess the hypothesis if month or season of birth had any bearing on the later development of cataract.

\section{Subjects and methods}

The 723 cases and 1217 controls were pooled from the two original case-control studies of cataract in Oxfordshire. ${ }^{2}{ }^{3}$ Cases were those aged 50-79 years admitted to the Oxford Eye Hospital for cataract surgery. Controls were recruited from other hospital departments, mostly ear, nose and throat and dermatology, and from the age-sex registers of local general practitioners. The age-sex distribution of the controls was matched to that of the cases. The overall response rates were $97 \%$ for cases and $94 \%$ for controls. Cases and controls were interviewed in the same way by the same interviewers using the same forms. The date of interview was noted and subjects were asked for date of birth, to calculate age. For the present paper date of birth was used to determine month and thus season of birth.

Data were entered into the university's main computer and combined from the two studies before analysis using the sAS statistical package
Table 1 Cases and controls by month of birth

\begin{tabular}{lrcl}
\hline & Controls & Cases & $\%$ Cases \\
\hline January & 101 & 68 & 40.2 \\
February & 99 & 57 & 36.5 \\
March & 108 & 67 & 38.3 \\
April & 100 & 67 & 40.1 \\
May & 117 & 66 & 36.1 \\
June & 112 & 51 & 31.3 \\
July & 96 & 55 & 36.4 \\
August & 102 & 68 & 40.0 \\
September & 95 & 57 & 37.5 \\
October & 103 & 61 & 37.2 \\
November & 99 & 51 & 34.0 \\
December & 84 & 55 & 39.6 \\
Total & 1216 & 723 & 37.3 \\
\hline
\end{tabular}

$\chi^{2}=5.53 ; p=0.9$. Not significant.

Table 2 Cases and controls by season of birth

\begin{tabular}{lcll}
\hline & Controls & Cases & $\%$ Cases \\
\hline Winter & 284 & 180 & 38.8 \\
Spring & 325 & 200 & 38.1 \\
Summer & 310 & 174 & 36.0 \\
Autumn & 297 & 169 & 36.3 \\
Total & 1216 & 723 & 37.3 \\
\hline
\end{tabular}

$\chi^{2}=1.17 ; \mathrm{p}=0.76$. Not significant.

(SAS Institute Inc, Cary, NC, USA). ${ }^{8}$ Analysis was by the $\chi^{2}$ test for categorical variables. Seasons were set with December to February taken as winter, March to May as spring, June to August as summer, and September to November as autumn. Odds ratios were calculated from contingency tables and confidence intervals calculated as described. ${ }^{3}$

\section{Results}

Each of the control groups, seven in the two original studies, was matched for age-sex distribution to the cases so the overall match was excellent. ${ }^{8}$ The data were analysed first for month of birth to see if some months had a greater proportion of cases than others. The results show no apparent differences (Table 1). There does not seem to be any excess risk associated with certain months of birth.

As any risk might be associated with a seasonal availability of food analysis was carried out by the broader periods of seasons (Table 2). No season seemed to confer a particular risk of cataract.

With the large numbers of subjects available in the combined studies it is possible to divide the population in other ways so we could explore whether there was an excess risk related to season for one sex rather than another or on age group rather than another. For example it might be thought that females could have been more at risk of underfeeding when young; or that any period of risk might have been confined to the early part of the century. The effect of season of birth was first analysed for 
Table 3 Season of birth as a risk factor for cataract in men

\begin{tabular}{llcl}
\hline & Controls & Cases & $\%$ Cases \\
\hline Winter & 131 & 93 & 41.5 \\
Spring & 151 & 97 & 39.1 \\
Summer & 141 & 73 & 34.1 \\
Autumn & 129 & 79 & 38.0 \\
Total & 552 & 342 & 38.3 \\
\hline
\end{tabular}

$\chi^{2}=2.65 ; \mathrm{p}=0.45$. Not significant.

Table 4 Season of birth as a risk factor in women

\begin{tabular}{llrl}
\hline & Controls & Cases & $\%$ Cases \\
\hline Winter & 153 & 87 & 36.2 \\
Spring & 174 & 103 & 37.1 \\
Summer & 169 & 101 & 37.4 \\
Autumn & 168 & 90 & 34.9 \\
Total & 664 & 381 & 36.5 \\
\hline
\end{tabular}

$\chi^{2}=0.45 ; p=0.93$. Not significant.

Table 5 Season of birth as a risk factor in the age range 50-69 years

\begin{tabular}{llcl}
\hline & Controls & Cases & $\%$ Cases \\
\hline Winter & 125 & 83 & 39.9 \\
Spring & 149 & 85 & 36.3 \\
Summer & 145 & 69 & 32.2 \\
Autumn & 130 & 73 & 36.0 \\
Total & 549 & 310 & 36.1 \\
\hline
\end{tabular}

$\chi^{2}=2.69 ; \mathrm{p}=0.44$. Not significant.

Table 6 Season of birth as a risk factor in the age range 70-79 years

\begin{tabular}{llrl}
\hline & Controls & Cases & $\%$ Cases \\
\hline Winter & 159 & 97 & 37.9 \\
Spring & 176 & 115 & 39.5 \\
Summer & 165 & 105 & 38.9 \\
Autumn & 167 & 96 & 36.5 \\
Total & 667 & 413 & 38.2
\end{tabular}

$\chi^{2}=0.599 ; \mathrm{p}=0.897$. Not significant.

men (Table 3). No significant effect of season was found. Similarly there was no effect for women (Table 4). There did appear to be a slight excess of births in the spring but that applied to both sexes and to both cases and controls (Tables 3 and 4).

Subdividing by age it was possible to test the hypothesis for those born roughly before the first world war and those born later. Season was not associated with cataract for either the younger group (Table 5) or the older group (Table 6).

\section{Discussion}

The choice of cases and controls and possible sources of bias were discussed in papers on the two constituent studies. ${ }^{2}{ }^{3}$ Combining the data from both studies provides numbers large enough to allow subdivision of the population into groups that may have different risk associations. For example, it was possible to show that female diabetics had an excess risk of cataract compared with male diabetics. ${ }^{8}$ In the present analysis we tested the hypothesis that risk of cataract in later life might in part be determined by season of birth as has been shown for other diseases. No support for this hypothesis could be found either in the whole cataract population, or in either men and women separately, or in older and younger groups analysed separately. We have to con- clude that season of birth has no effect on the overall risk of cataract in an Oxfordshire population. Cataracts in this study were not subdivided so it is possible that a relation could be present for a small subset of total cataracts, but it is unlikely that there could be a major effect in a major group of cataracts. The advisability of dividing cataracts into different morphological groups has been discussed at some length by several authors, but most significant results have been on pooled cataracts..$^{2-5}$ 9-11 No major new risk factor has been identified by morphological subdivision and most cataracts are of mixed type. Our results do not rule out a role for season of birth in other countries where nutritional deprivation was more common than it was in Britain in the first four decades of this century. After submission of this paper Professor Weale sent us a copy of a paper on season of birth and cataract to be published shortly. ${ }^{12} \mathrm{He}$ found an excess of cataract patients born in the spring on the Indian subcontinent. This overall excess was accounted for by an excess of posterior subcapsular cataract, especially in combination with nuclear cataract. Even here a risk factor was identified first for total cataract and then pinned down to one morphological type. There were no control groups so the problem of nonuniform birth rate was dealt with by use of a published birth index for India. Our Oxfordshire population had few members from ethnic minorities (less than 5\%) and so would not identify effects confined to those populations. It is likely that season of birth is more important to those born on the Indian subcontinent than to those born in the UK.

We thank RNIB, the TFC Frost Charitable Trust, and Research into Ageing for financial support. We are grateful to consultants of the Oxford Eye Hospital, ENT Department of the Radcliffe Infirmary, and the Slade Hospital; and to local general practitioners for access to their patients. We are grateful to Professor R A Weale for sending us a copy of his paper before publication.

1 Harding JJ Cataract: biochemistry, epidemiology and pharmacology. London: Chapman and Hall, 1991.

2 Van Heyningen R, Harding JJ. A case-control study of cataract in Oxfordshire: some risk factors. Br $\mathcal{f}$ Ophthalmol ract in Oxfords

3 Harding JJ, Harding RS, Egerton M. Risk factors for cataract in Oxfordshire: diabetes, peripheral neuropathy, myopia, glaucoma and diarrhoea. Acta Ophthalmol 1989; 67:510-17.

4 Donelly CA, Seth J, Clayton RM, et al. Some blood plasma constituents correlate with human cataract. $\mathrm{Br} \mathcal{F}$ Ophthalmol 1996;79:1036-41.

5 Tavani A, Negri E, la Vecchia C. Food and nutrient intake and risk of cataract. Ann Epidemiol 1996;6:41-6.

6 Poulsen P, Vaag AA, Kyvik KO, et al. Low birth is associated with NIDDM in discordant monozygotic and dizygotic twin pairs. Diabetologia 1997;40:439-46.

7 Moore SE, Cole TJ, Poskitt EME, et al.Season of birth predicts mortality in rural Gambia. Nature 1997;388:434.

8 Harding JJ, Egerton M, van Heyningen R, et al. Diabetes, glaucoma, sex, and cataract: analysis of combined data from
two case-control studies. Br f Ophthalmol 1993;77:2-6.

9 Clayton RM, Cuthbert J, Duffy J, et al. Some risk factors associated with cataract in SE Scotland: a pilot study. Trans Ophthalmol Soc UK 1982;102:331-6.

10 Clayton RM, Cuthbert J, Seth J, et al. Epidemiological and other studies in the assessment of factors contributing to cataractogenesis. Ciba Fndn Symp 1984;106:25-47.

11 Chen TT, Hockwin O, Dobbs R, et al. Cataract and health status: a case-control study. Ophthalmic Res 1988;20:1-9.

12 Weale RA. Cataract, glaucoma and season of birth amongst patients born on the Indian subcontinent. Ind $\mathcal{F}$ Ophthalmol 1998; (in press). 